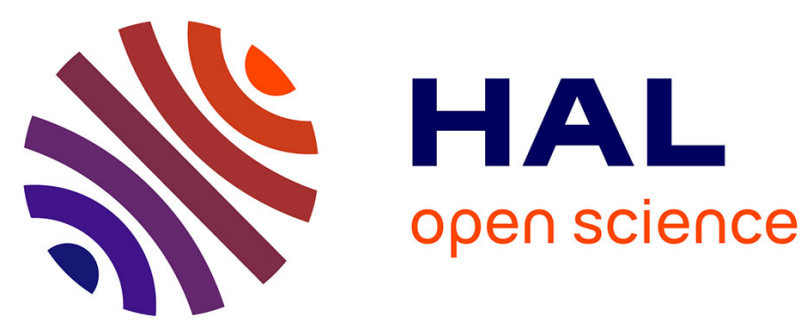

\title{
Dynamic of a Space Charge in Gamma-Irradiated Cross-Linked Polyethylene (XLPE)
}

C Mouchache, Virginie Griseri, N Saidi-Amroun, G. Teyssedre, S Mouaci, M Saidi

\section{- To cite this version:}

C Mouchache, Virginie Griseri, N Saidi-Amroun, G. Teyssedre, S Mouaci, et al.. Dynamic of a Space Charge in Gamma-Irradiated Cross-Linked Polyethylene (XLPE). IEEE Internat. Conf. on Dielectrics (ICD), Valencia, Spain, 5-9 July 2020., Jul 2020, Valencia, Spain. pp. 409-412. hal-03003137

\section{HAL Id: hal-03003137 https://hal.science/hal-03003137}

Submitted on 13 Nov 2020

HAL is a multi-disciplinary open access archive for the deposit and dissemination of scientific research documents, whether they are published or not. The documents may come from teaching and research institutions in France or abroad, or from public or private research centers.
L'archive ouverte pluridisciplinaire HAL, est destinée au dépôt et à la diffusion de documents scientifiques de niveau recherche, publiés ou non, émanant des établissements d'enseignement et de recherche français ou étrangers, des laboratoires publics ou privés. 


\title{
Dynamic of a Space Charge in Gamma-Irradiated Cross-Linked Polyethylene (XLPE)
}

\author{
${ }^{1}$ C. Mouchache, ${ }^{2}$ V. Griseri, ${ }^{1}$ N.Saidi-Amroun, ${ }^{2}$ G. Teyssèdre, ${ }^{1}$ S. Mouaci and ${ }^{1}$ M. Saidi \\ ${ }^{1}$ Material Physics Laboratory, Physics Faculty, University of Sciences and Technology (USTHB) \\ BP 32 El-Alia, Bab-Ezzouar, Algiers, Algeria, \\ ${ }^{2}$ LAPLACE, Université de Toulouse and CNRS, 118 Route de Narbonne, 31062 Toulouse Cedex 9, France.
}

\begin{abstract}
The aim of the present work is to study the dynamics of the space charge in cross-linked polyethylene (XLPE) irradiated by gamma rays. For this purpose, film samples peeled from cables have been irradiated with gamma rays at total dose up to $100 \mathrm{kGy}$, in air at room temperature. To investigate the impact of the irradiation on the electrical behavior, space charge measurements were achieved in ambient conditions after the irradiation using Pulsed Electro Acoustic (PEA) method. The space charge measurements on the irradiated XLPE under an electric field of $40 \mathrm{kV} / \mathrm{mm}$ show the development of twoheterocharge regions adjacent to the electrodes. This is in mark contrast with the behavior of un-irradiated XLPE with space charge pattern dominated by charge injection. The charge accumulated during the polarization step persists during the relaxation and is stable after 1 hour.
\end{abstract}

\section{INTRODUCTION}

Cross-linked polyethylene (XLPE) is one of the most used materials in power cable industry because of his good dielectric and thermal properties. Space charges play an important role in the electrical behavior of XLPE, the reason why so many works are carried out to understand the origin and the impact of the formation of space charge on insulation reliability [1, 2]. However, the space charge in XLPE is still not fully understood and many processes can be involved in generation and accumulation of charges. Though the presence of space charge in XLPE under nuclear radiation environment has been investigated in some researches [3, 4], the gross of the work is on the impact of field, temperature and material compounding, especially in the perspective of developing DC insulations. Ionizing radiation certainly constitutes a threat regarding space charge properties and insulation endurance. Indeed, when a polymeric insulation is submitted to an ionizing irradiation environment such as space environment for aircrafts or nuclear reactor for power systems, its dielectric and mechanical properties are altered due to chain scission, crosslinking and oxidation $[3,5]$.

In this paper, we investigate the impact of gamma irradiation on electrical behavior of XLPE. The experimental results consist on charge distribution in cross-linked polyethylene (XLPE) obtained by the pulsed electro-acoustic (PEA) method and the result show remarkable difference between irradiated and non-irradiated XLPE. Focus is given on the dynamic and origin of charges generated in the bulk of XLPE materials during polarization under dc field.

\section{EXPERIMENTAL SET-UP}

\section{A. XLPE Samples}

The cross-linked polyethylene (XLPE) was chosen as test material in the present study, since available directly from real power cables. Indeed, in the frame of the European project Artemis [6, 7], HVAC cables with $15 \mathrm{~mm}$ thick insulation were produced, and some sections of the produced cables were submitted to electrical and thermal aging in various conditions. Also, the cables were submitted to a wealth of electrical and structural characterization in previous works [6, 7] to reveal the impact of aging. Samples were used later after the project to investigate ageing under various electrical, thermal and radiation conditions [8, 9]. XLPE samples used in the present work were taken from rolls produced in the frame of the project, having thickness of $150 \mu \mathrm{m}$ and width of 80 $\mathrm{mm}$ and stored in ambient conditions.

The sample were exposed to gamma irradiation in air at room temperature. The irradiation was made using ${ }^{60} \mathrm{Co}$ source with a dose rate of $23 \mathrm{~Gy} / \mathrm{min}$, and a total dose up to $100 \mathrm{kGy}$. We noticed a slight change in color after the irradiation: the samples then become more yellowish. A. Charlesby et al reported on similar yellowing of polyethylene irradiated with gamma rays [10]. Thermal ageing also produced yellowing on Artemis cables, presumably due to degradation of the antioxidant [7].

\section{B. Space charge measurements}

Pulsed Electro-Acoustic -PEA measurements were achieved using a test cell provided by TechImp, Italy, suitable for the $150 \mu \mathrm{m}$ thick samples used here. Experiments were achieved in air in an oven at a controlled temperature of $25^{\circ} \mathrm{C}$. Pulsed voltages of $250 \mathrm{~V}$ amplitude, $8 \mathrm{~ns}$ width and $2 \mathrm{kHz}$ repetition rate were used throughout the voltage cycle.

The sample was placed in sandwich configuration between the electrodes of the PEA cell, being ground Al electrode and semiconductor (carbon black doped polymer) as HV electrode. The space charge profiles were recorded in $20 \mathrm{~s}$ intervals, under the application of dc field of $40 \mathrm{kV} / \mathrm{mm}$ with positive polarity voltage for 1 hour followed by relaxation under $0 \mathrm{~V}$ for 1 hour. The voltage rising/falling rate was $1 \mathrm{kV} / \mathrm{mm} / \mathrm{s}$ for electric field to reach the desired level. 


\section{RESULTS}

\section{A. Space charges in non-irradiated XLPE}

Fig. 1 shows the charge developed in non-irradiated XLPE during polarization using DC field of $40 \mathrm{kV} / \mathrm{mm}$ for 1 hour. All profiles shown in this work are with 3 min interval time recording. As reported in previous work [11], the dominant mechanism observed on the recorded profiles for nonirradiated XLPE is the injection of charges followed by trapping near the electrode, forming homocharge. We clearly observe an injection of negative charge from the ground electrode, and the injection and charge accumulation processes are continuous during 1 hour stressing time. Indeed, the amount of negative charge grows slightly over time. It is also noticed that a small amount of positive charge was injected from the anode. However, the peak detected does not evolve with time. The influence charge on the ground electrode decreases over time, whereas the one at the HV electrode increases, due to the influence of the negative injected that creates positive image charges at both electrodes. The dominance of negative charges in the space charge profiles of XLPE was reported by Tzimas et al [12] for the same kind of samples taken from the Artemis program. It was also shown that steady state charging state could take several hours to be reached. It is therefore clear that the $1 \mathrm{~h}$ charging time used here is not enough to reach a steady state situation regarding charge build-up.

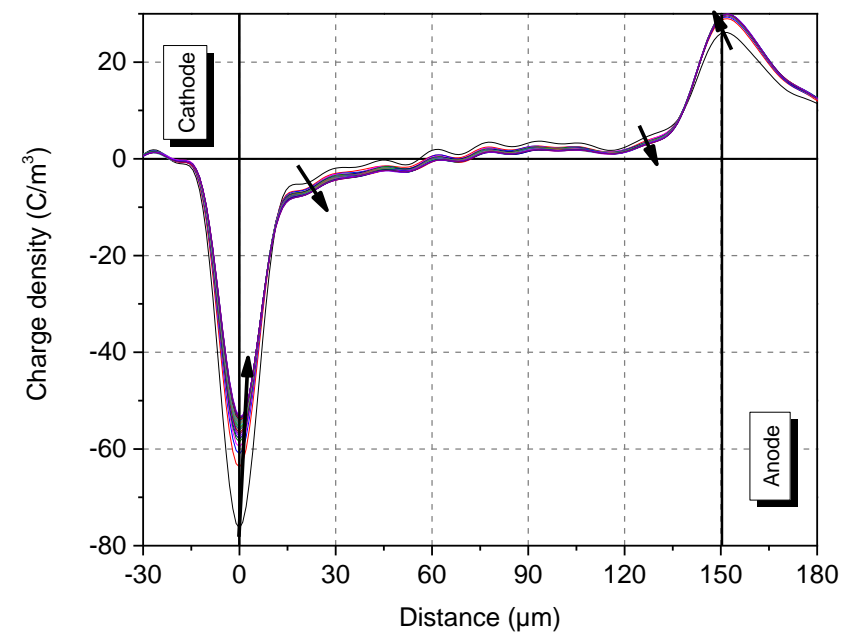

Fig. 1. Space charge profile recorded on a non-irradiated XLPE, during $1 \mathrm{~h}$ of polarisation under $40 \mathrm{kV} / \mathrm{mm}$ [12]. Profiles shown were obtained in $3 \mathrm{~min}$ interval time.

Fig. 2 shows the time evolution of the space charge distribution when the applied field is removed. A negative charge is detected in the bulk of the sample and it seems to be spread homogeneously in all the insulation. The amount of negative charge decreases slowly during 1 hour. The positive induced charges on both electrodes represent the image of the negative charges trapped in the bulk.

Fig. 3 shows the distribution of the electric field all long the thickness. The electric field decreases slightly in the bulk with the increase of charging time, the electric field decreases from $50 \mathrm{kV} / \mathrm{mm}$ into $45 \mathrm{kV} / \mathrm{mm}$ in the end of polarization. The local electric field appear to be nearly homogeneously spread into the insulation.

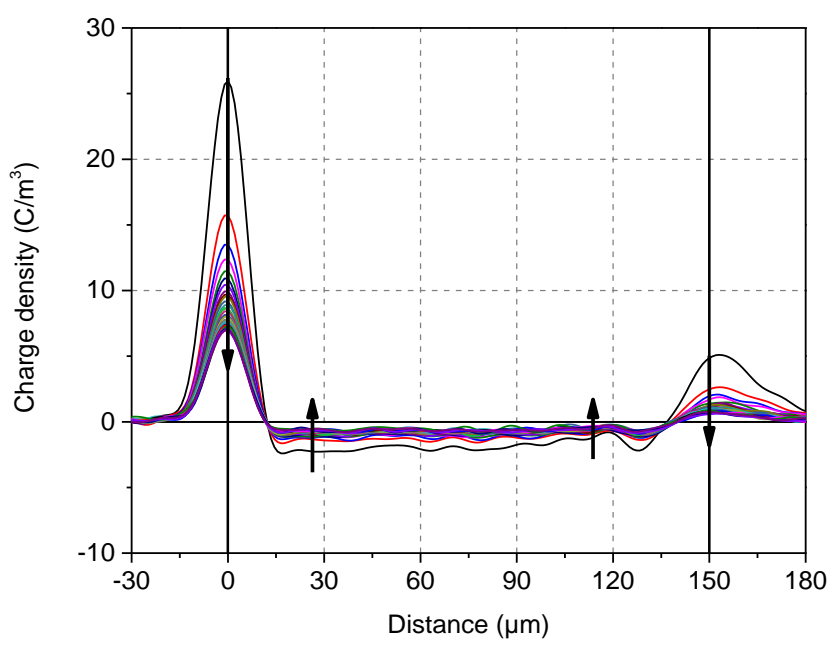

Fig. 2. Space charge profile recorded on a non-irradiated XLPE, during $1 \mathrm{~h}$ of relaxation in Volt-off [11].

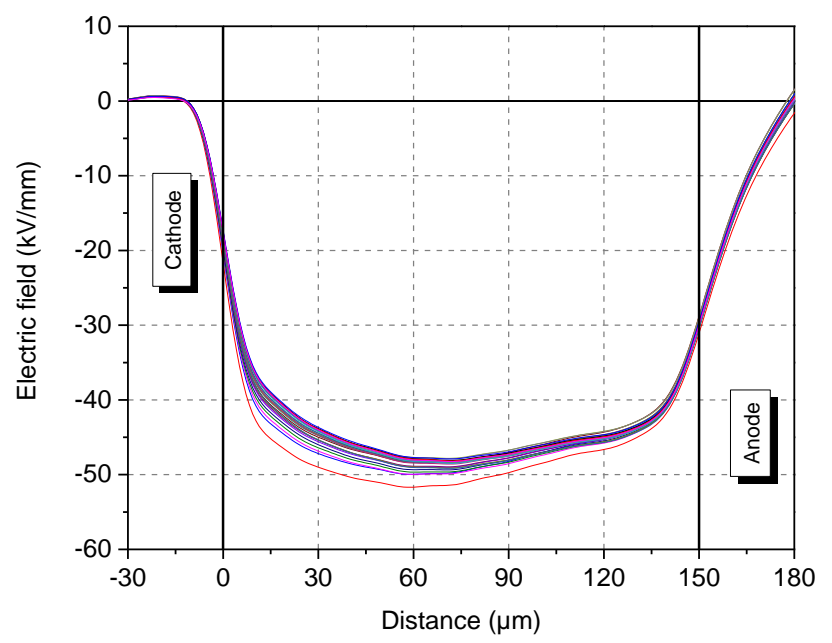

Fig. 3. Electric field distribution profiles recorded on a non-irradiated XLPE.

\section{B. Space charge in irradiated XLPE}

The measurement results of space charge distribution in XLPE irradiated by gamma rays with a total dose of $100 \mathrm{kGy}$ are represented in Fig. 4 for 1 hour stressing time under applied DC field of $40 \mathrm{kV} / \mathrm{mm}$. The profile obtained before DC stressing reveals that there is no detectable amount of charge in the material, at least as net charge is concerned.

Upon DC stressing, negative and positive charge regions are gradually developed from the first moments of the application of external stress and the amount of heterocharge increases rapidly and continually during this period. The charge clouds on the profiles are adjacent to the anode for negative charges and to the cathode for positive ones. It is also noticeable that the charged regions are well symmetrical in the shape of the peak with the same maximum values of charge density. 
The peak of influence charge recorded on the anode side shows a clear though slight increase in time. The variation is greater, or at least clearer at the cathode owing to the fact that the grounded electrode is adjacent to the piezoelectric sensor, hence the charge is better resolved than at the anode.

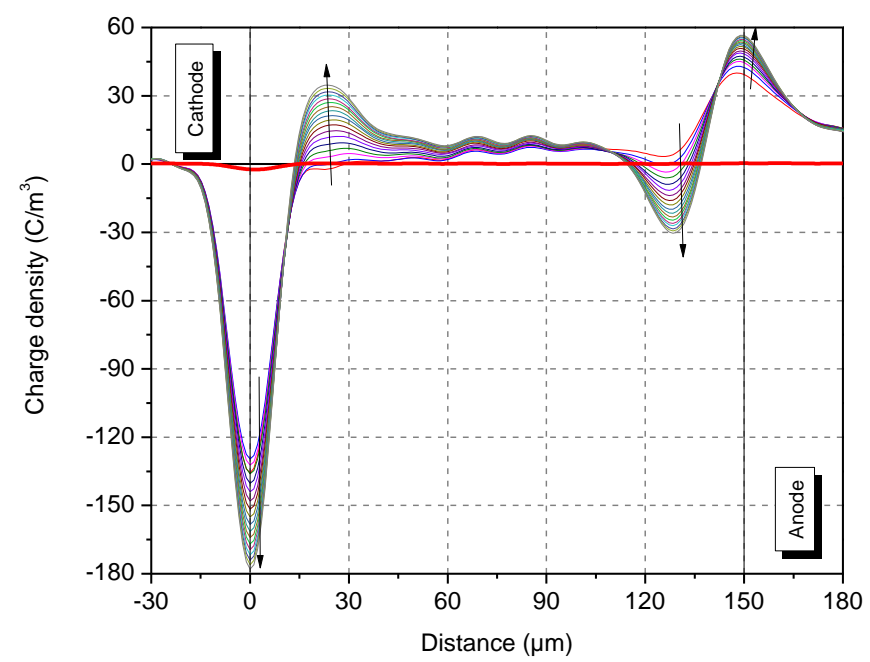

Fig. 4. Space charge profile recorded on a XLPE sample pre-irradiated with gamma ray. During $1 \mathrm{~h}$ of polarization under $40 \mathrm{kV} / \mathrm{mm}$. The profile obtained prior to DC polarization is shown as bold red line.

The space charge profiles recorded during relaxation of the charge (0V applied) are presented in Fig. 5. The charges accumulated during the polarization step decrease slightly in 1 hour time. The maximum value in positive charge drops from $35 \mathrm{C} / \mathrm{m}^{3}$ to $30 \mathrm{C} / \mathrm{m}^{3}(14 \%)$. The decrease in the negative charge peak amplitude is faster than for the positive one, the drop in peak amplitude being from $-35 \mathrm{C} / \mathrm{m}^{3}$ to $-25 \mathrm{C} / \mathrm{m}^{3}$ $(28 \%)$. These variations are reflected on the image charge peaks.

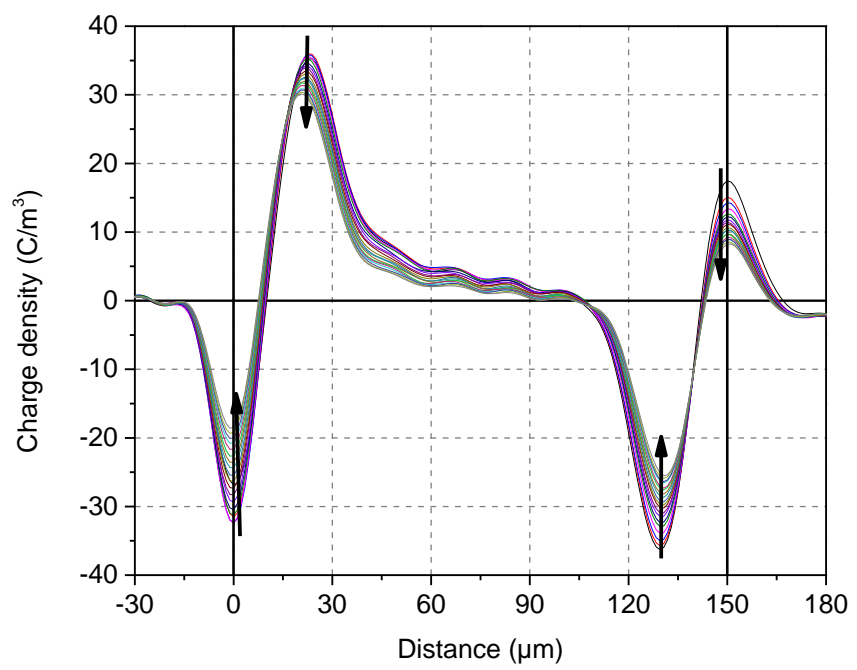

Fig. 5. Space charge profiles recorded on a XLPE pre-irradiated by gamma ray, during $1 \mathrm{~h}$ of relaxation after polarization for $1 \mathrm{~h}$ under $40 \mathrm{kV} / \mathrm{mm}$.

\section{DISCUSSION}

The formation of large amount of negative and positive heterocharges in gamma-irradiated XLPE is a completely new behavior compared to the non-irradiated XLPE. Such a difference in the charge distribution is obviously related to the impact of the energy deposited by gamma ray in the material by causing reconfiguration of the electrical properties and presumably of the structure of XLPE. When the injection of charge from electrodes is the apparent mechanism responsible of space charge build-up in non-irradiated XLPE (Fig. 1, 2), in the gamma irradiated XLPE the source of charges is apparently from the bulk. With the same stress applied on the non-irradiated and irradiated XLPE the charge developed in virgin XLPE is an order of magnitude less than in irradiated XLPE. In the irradiated sample the charge injection process was not observed or at least the heterocharge setting at the interface is much more important than the injected charge.

Compared to irradiation by an electron beam, where primary electrons were deposited and the deposited dose was not homogeneous along the thickness [11], gamma-rays are much more penetrating, producing homogeneous irradiation. As seen in Fig. 4, no charge was detected prior to voltage application.

The main question is on the origin of the charges being accumulated. Irradiation may produce electron-hole pairs or ion pairs into the material that can subsequently be driven toward the electrodes under application of the field. As there is no mass transfer across the interfaces, the ions could be accumulated near the interfaces. Fig. 6 provides an analysis of the charge decay kinetics with distinguishing the behavior of positive and negative charges. Charge, taken in absolute value, was integrated in the regions indicated in the caption. Though there is a somewhat higher amount of positive charges than of negative ones, the decay kinetics are similar.

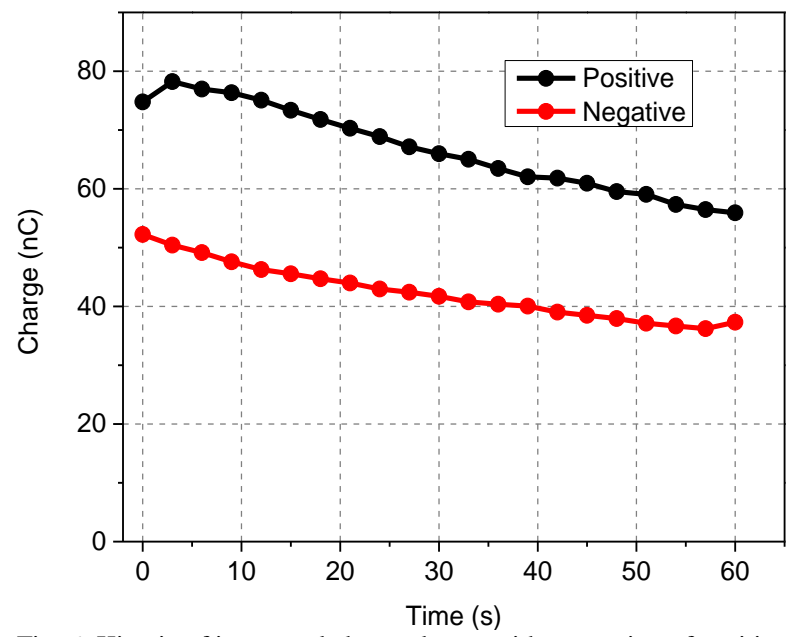

Fig. 6. Kinetic of integrated charge decay, with separation of positive and negative charges. The charge was integrated in the region from $10 \mu \mathrm{m}$ to 105 $\mu \mathrm{m}$ for positive charges and $105 \mu \mathrm{m}$ to $142 \mu \mathrm{m}$ for negative ones.

The interpretation in terms of ions movement would be consistent with the relative slow charge build up and with the 
fact that symmetrical charge patterns are observed. The net charge build-up could be explained by the movement of one polarity ions causing depletion on one side and accumulation on the other side. Radiation may also produce ionisable molecules or groups that could be dissociated under the effect of field and end with the same space charge features as with pre-existing ions.

A second possibility is that an interface layer with enhanced oxidation is present near both electrodes. The coloring of cables indeed reveals that chemical modification of the material has occurred. Fu et al [3] reported on very different space charge features depending whether gamma-irradiation was achieved in air or in neutral atmosphere. The space charge profile after irradiation at $100 \mathrm{kGy}$ in air was much more complicated than when irradiating in vacuum and nitrogen at same dose. Resorting to low density polyethylene, oxidation was recognized as one of the main mechanisms inducing changes by the irradiation $[13,14]$. Even analyzing the shape of space charge peak charge could be a way to identify the oxidized region [15].

Oxidation could have two consequences: the formation of a polymer region near the surface with different electrical conductivity than in the bulk, and/or the formation of blocking layers for electronic carriers travelling through a sample with enhanced bulk conductivity due to irradiation. In the first case, symmetrical space charge patterns would be expected, and given the sign of the charge, the conductivity would be lower in the oxidized regions. The time for charge release would be slower than for build-up as the driving field is lower. In the second case, there is no a priori reason to get symmetrical charge patterns, both in charge amount and in build-up kinetics.

\section{CONCLUSION}

Gamma-irradiation effects on space charge build-up was investigated in $150 \mu \mathrm{m}$ thick cable peelings taken from HVAC cables. With such irradiation with $100 \mathrm{kGy}$ dose achieved in air, substantial heterocharge build-up was observed at the two interfaces. The singularity in respect to previous works is the symmetrical features of the space charge being developed, considering the amount of charges, the peak shape and the build-up and decay kinetics. The behavior observed here could be related to the formation of an oxidized region near the interfaces. The electrical conductivity gradient introduced by such layer could be a reason for the obtained space charge patterns.

\section{ACKNOWLEDGMENT}

The authors are grateful to the Director and staff (especially M. R. Yefsah) of the Nuclear Research Centre of Algiers for the provision of the irradiation facility. The work is supported by French-Algerian Tassili research program in the frame of Partenariat Hubert Curien (PHC).

\section{REFERENCES}

[1] G. Teyssedre, C. Laurent, G.C. Montanari, F. Palmieri, A. See, L.A. Dissado, and J.C. Fothergill, "Charge distribution and electroluminescence in cross-linked polyethylene under dc field", $J$. Phys. D, vol. 34, pp. 2830-2844, 2001.

[2] D. He, X. Wang, H. Liu, Q. Li, and G. Teyssèdre, "Space charge behavior in XLPE cable insulation under ac stress and its relation to thermo-electrical aging", IEEE Trans. Dielectr. Electr. Insul., vol. 25, pp. 541-550, 2018.

[3] M. Fu, G. Chen, L. A. Dissado, J. C. Fothergill, and C. Zou, "The effect of gamma irradiation on space charge behaviour and dielectric spectroscopy of low-density polyethylene," Proc. IEEE-ICSD, pp. 442445, 2007.

[4] M. Kojima, Y. Tanaka, T. Takada, and Y. Ohki, "Measurement of residual space charge distribution in $\gamma$-irradiated polyethylene", Proc. 4th ICPADM, pp. 479-482, 1994.

[5] G. M. Sessler, "Charge dynamics in irradiated polymers", IEEE Trans. Electr. Insul., vol. 27, pp. 961-973, 1992.

[6] J. C. Fothergill et al., "Electrical, microstructural, physical and chemical characterization of HV XLPE cable peelings for an electrical aging diagnostic data base", IEEE Trans. Dielectr. Electr. Insul., vol. 10, pp. 514-527, 2003.

[7] G. Teyssedre, C. Laurent, and G.C. Montanari, "Semi-quantitative analysis of photoluminescence in thermoelectrically aged cables: IIAnalysis of a population of cables", IEEE Trans. Dielectr. Electr. Insul., vol. 16, pp. 1189-1198, 2009.

[8] V. Griseri, G. Teyssedre, N. Saidi-Amroun, S. Mouaci, C. Mouchache, and M. Saidi, "Dynamic of space charge in electron-beam irradiated cross-linked polyethylene". Proc. IEEE-ICD, pp. 601-604, 2018.

[9] A. Tzimas, S.M. Rowland, and L.A. Dissado, "Effect of electrical and thermal stressing on charge traps in XLPE cable insulation", IEEE Trans. Dielectr. Electr. Insul., vol. 19, pp. 2145-2154, 2012.

[10] A. Charlesby, Atomic Radiation and Polymers, Pergamon, New York, 1960.

[11] C. Mouchache, V. Griseri, N. Saidi-Amroun, G. Teyssèdre, S. Mouaci and M. Saidi, "Space charge in electron-beam irradiated cross-linked polyethylene (XLPE): Charge implantation and release from the bulk," Proc. IEEE-CEIDP, pp. 482-485, 2019.

[12] A. Tzimas, S. M. Rowland, L. A. Dissado, M. Fu, and U. H. Nilsson, "The effect of dc poling duration on space charge relaxation in virgin XLPE cable peelings", J. Phys. D: Appl. Phys., vol. 43, pp. 215401-1/10, 2010

[13] D. Kostoski, J. Dojcilovic, L. Novakovic and E. Suljovrujic, "Effects of charge trapping in gamma irradiated and accelerated aged low-density polyethylene", Polym. Degrad. Stab., vol. 91, pp. 2229-2232, 2006.

[14] G. Chen, A. E. Davies and H. M. Banford, "Influence of radiation environments on space charge formation in $\gamma$-irradiated LDPE", IEEE Trans. Dielectr. Electr. Insul., vol. 6, pp. 882-886, 1999.

[15] G. Chen, A.E. Davies, B. Xi, "Charge formation and decay in $\gamma$ irradiated low-density polyethylene", Proc. 6th ICPADM, pp. 443-446, 2000. 